\title{
Knowledge Creation in Improving a Software Organisation
}

\author{
Pouya Pourkomeylian \\ Pouya.Pourkomeylian@astrazeneca.com
}

AstraZeneca R\&D Mölndal, S-431 83 Mölndal, Sweden

Tel: +463177617 96, Fax: +46317763730

Viktoria Institute, Box 620, 40530 Göteborg, Sweden

Key words: Software Process Improvement (SPI), Organisational Knowledge Creation (OKC).

\begin{abstract}
Software Process Improvement (SPI) is a systematic approach for improving the capabilities of a software organisation. This study shows the results of a collaborative research initiative in which an SPI project was conducted and analysed as organisational knowledge creation. The study explains how knowledge is created through transformation between tacit and explicit knowledge and through interaction between different organisational levels of actors. On the basis of our findings it is suggested that two types of knowledge are created in an SPI project based on completely different knowledge creation behaviour.
\end{abstract}

\section{INTRODUCTION}

Software development has existed as a discipline for more than forty years but has not yet become a disciplined process. Software projects are almost always later than expected, the costs of developing software are 
higher than planned, and the functionality and the quality of the final products (software and documentation) are lower than expected (Paulk, 1997). Software organizations have used different methods for improving software processes. The most recent approach for improving software processes is Software Process Improvement (SPI), which is a systematic approach toward changing software development practice.

The first step in improving software processes is to understand the current status of the software development process (Humphrey, 1989). One way of doing this is to make an assessment based on a model as a road map. During the past years software organisations have used different appraisal approaches to identify what should be improved in their software processes. The most popular assessment model is the Capability Maturity Model (CMM), which is a normative approach to software process improvement developed by the Software Engineering Institute (SEI) (Paulk, 1993). Other approaches include BOOTSTRAP (Kuvaja, 1994), SPICE (Thomson \& Mayhew, 1997), ami (ami, 1992), TickIT (TickIT, 1995), and TRILLIUM (Thomson \& Mayhew, 1997). Common for all these approaches is that they apply Total Quality Management (TQM) principles to SPI. After making an assessment further improvement activities should be planned and performed to create new or modified software processes.

Different reports have pointed out difficulties in performing SPI projects in practice (Curtis, 1996), (Debou, 1997), and (Goldenson and Herbsleb, 1995). An SPI effort is successful when the new or modified software processes are created and used in the organisation's daily practice and have been proven to function in achieving their goals. Success with SPI seems to depend on a complex mix of highly interrelated factors acting in different phases in an SPI project. Different factors such as scaling the SPI initiative, setting realistic goals, the complexity of organisational changes, and the organisational culture have made it difficult to achieve success in SPI initiatives (Goldenson \& Herbsleb, 1995), (Herbsleb et al., 1997), (Mashiko and Basili, 1997), and (Johansen and Mathiassen, 1998). But SPI has also been shown to be able to help organisations gain organisational benefits (Hayes and Zubrow 1995), (Larsen and Kautz 1997), and (Wohlwend and Rosenbaum 1994).

An organisation's software development practices are based on the existing knowledge of practitioners and managers about the software development practice (Arent and Norbjerg, 2000). To change software development practices the organisation should improve the practitioners' existing knowledge (both tacit and explicit) of the software practices. The created new or modified knowledge should then be transferred to all organisational levels to become part of the practitioners' daily work. Creating new or modified software processes in this way is a knowledge 
creation process in which different actors at different organisational levels are involved in creating different types of knowledge.

Some recent reports have reflected on the importance of creating and managing knowledge and learning issues for SPI initiatives. Arent and Norbjerg (2000) analysed how organisational knowledge creation process and learning can support SPI initiatives. Stelzer, Mellis, and Herzwum (1998) studied how principles and technologies from organisational learning can apply to SPI initiatives and become enablers of SPI success. Halloran (1999) investigated the relationship between an SPI approach and organisational learning. These studies indicate that the concept of knowledge creation and learning can support SPI initiatives. We believe that the concept of organisational knowledge creation has much to offer the SPI community, especially in the following three questions: 1) What types of knowledge are created as the result of performing an SPI project? 2) Which actors are involved in the knowledge creation process? 3) How do they interact to create knowledge?

As a framework to support the analysis of the SPI project this study has chosen Nonaka and Takeuchi's theory (see Nonaka and Takeuchi, 1995) because their theory explicitly deals with the fundamental process of knowledge creation and supports an understanding of the interaction between individuals, groups, and organisations in the knowledge creation process. This approach has demonstrated its usefulness in relation to SPI in a study by Arent and Norbjerg (Arent and Norbjerg, 2000) analysing the learning process in SPI.

\section{$1.1 \quad$ The Research Approach}

Using a collaborative practice research approach (see Mathiassen, 1998) this study has combined action research in combination with field experiment, and practice study aiming to change practice. Improving practice is the distinguishing feature of collaborative practice research and action research in general (Baskerville et al., 1996), (Mathiassen, 1998). The action research approach is chosen for this study because of its strong support in: 1) integrating research and practice, 2) involving practitioners in the problem being studied, 3 ) giving the possibility of introducing change at the same time the research is going on.

In this study an SPI project was done during the period of April 1999 to June 2000. Several practitioners (software engineers) were involved during both the evaluation of software projects and the improvement of software processes. The SPI-group including: software engineers, assisting consultants, and the author (leading the SPI project) working with improving software processes became a forum for evaluating the Software Engineering 
(SE) and the SPI practices, for creating and experimenting with new or modified software processes, and for learning about SPI in practice. Action research in this study was set up to improve three main software processes using the IDEAL model (see section 2.1). Field experiments were set up as controlled research efforts in which the created software processes were tested in one selected software pilot project to show the effects of the created processes. Focused practice studies were initiated to learn about the current maturity level of the software organisation.

One focused SPI practice was to make a CMM assessment to establish the current maturity of software processes. To collect data about the current capability of software processes at the software organisation a modified CMM assessment based on a method called Questionnaire Based Assessment (QBA) (see Arent and Iversen, 1996) was made for three different software development projects chosen from two different software development groups. The following Key Practice Areas (KPAs) were included in the assessment to identify software process problems: 1) Software Project Planning, 2) Requirements Management, 3) Software Project Tracing and Oversight, 4) Software Quality Assurance, 5) Software Configuration Management.

Project managers and developers of three selected software development projects answered the CMM-based questionnaire. The collected data were statistically analysed and proposals were developed for improving software development projects on the basis of the results of analysed qualitative data collected from the assessment, the software process improvement literature, and other quality improvement findings from earlier quality activities in the software organisation. The SPI-group met at least eight times throughout the 14-month period for planning and organising SPI initiatives and discussing difficulties and problems. The new and modified software processes will be implemented in the whole organisation starting in August 2000. The results and lessons learned during the improvement phase have been documented. These lessons have been both interpretative, i.e. helped us to understand the practice, and normative, i.e. helped us to design new or modified software processes and improve the practice. Knowledge gained and experience from doing this research in practice have created new research activities for further studies. The author actively participated in the practical work with SPI in the organisation, such as conducting the CMM-based assessment, running and participating in workshops and seminars, performing interviews and analysing results.

The section below discusses the software process improvement and organisational knowledge creation concepts and presents the framework for the analysis. Section 3 presents the case. Section 4 presents a map of the knowledge creation process in the SPI project and discusses the findings 
according to the three questions mentioned above, and section 5 concludes the paper by presenting the lessons learned and pointing out areas for further research.

\section{BACKGROUND}

Software Process Improvement (SPI) was originally developed at the Software Engineering Institute (SEI) at the Carnegie Mellon University and was based on ideas presented by Humphrey (see Humphrey, 1989). According to Aaen et al. (2000) SPI is based on a number of ideas that offer answers to specific concerns. SPI has three fundamental concerns: the management of SPI activities, the approach taken to guide the SPI initiatives, and the perspective used to focus attention on the SPI goal(s).

The management of SPI initiatives is based on three ideas: 1) the SPI activities are organised in a dynamic fashion, 2) all improvement efforts are carefully planned and 3) feedback on effects on software engineering practices is ensured. The approach to SPI initiatives is guided by three additional ideas: 1) SPI is evolutionary in nature, 2) SPI is based on idealised, normative models of software engineering and 3) SPI is based on a careful creation and development of commitments between the involved actors. Finally the perspective forward the SPI goal is dominated by three ideas: 1) SPI is focused on software processes, 2) the practitioners' competencies are seen as the key resource and 3) SPI aims to change the context of the software operation to create sustainable support for the actors involved. The basic idea in SPI is to focus on software processes as social institutions with a complex interplay of people, methods, tools and products (Aaen et al. 2000).

SPI is focused on improving software processes based on practitioners' ideas and experiences. This involves capturing practitioners' tacit knowledge (know-how) and transferring it to explicit knowledge, which should then be combined with the organisation's other explicit knowledge prepared for use in practice by all practitioners in different organisational levels.

\subsection{The IDEAL Model}

A popular model in the field of SPI that is suitable for assistance in managing SPI initiatives for implementing organisational changes is the IDEAL model (see McFeeley, 1996). As shown in figure 1 the IDEAL model considers five phases (Initiating, Diagnosing, Establishing, Acting and Learning) of a software process improvement initiative, which provide a 
continuous loop through the steps necessary for software process improvement (McFeely, 1996).

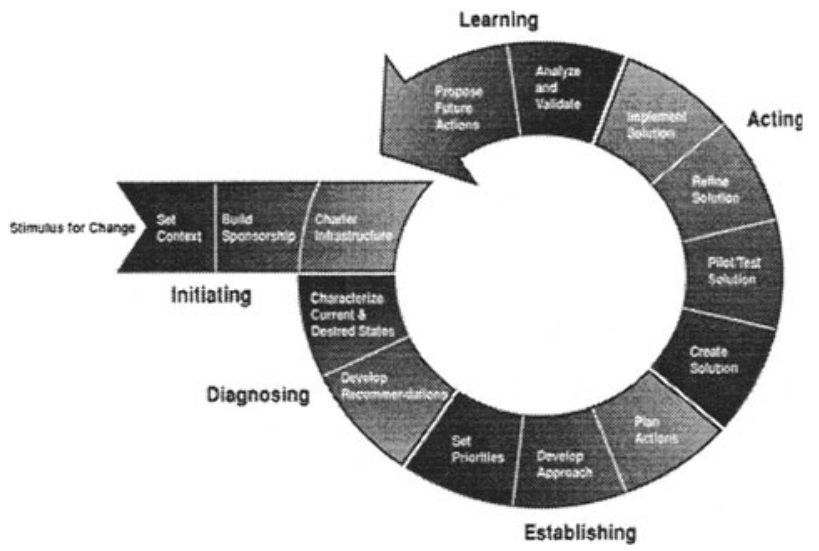

Figure 1. The IDEAL Model (Gremba and Myres 1997)

Once the first cycle of SPI has been completed there will be a need to regularly repeat the entire process. However, the ultimate goal in organisations should be to succeed in achieving process implementation in the whole organisation. This should lead to the creation of a process culture in which process discipline prevails. Our intention in using the IDEAL model was to establish successful improvement activities and infrastructures for SPI initiatives within the software organisation. This study includes the Initiating, Diagnosing, Establishing, and some parts of the Acting and Learning phases.

\subsection{Organisational Knowledge Creation}

Nonaka and Takeuchi (1995) use two dimensions of knowledge creation to explain the process of organisational knowledge creation: 1) the ontological and 2) the epistemological.

The ontological dimension focuses on individual knowledge creation. The organisation supports creative individuals or provides a context for them in which to create knowledge. Organisational knowledge creation is understood as a process that "organisationally" amplifies the knowledge created by individuals and crystallises it as a part of the knowledge network of the organisation. This process takes place within an expanding "community of interaction", which crosses intra- and inter-organisational levels and boundaries. 
For the epistemological dimension Nonaka and Takeuchi (1995) draw on Michael Polanyi's (1966) distinction between explicit knowledge and tacit knowledge. Explicit knowledge refers to knowledge that is transmittable in formal, systematic languages. It can be articulated in formal languages including grammatical statements, mathematical expressions, specifications, manuals and so forth. It can be transmitted across individuals formally and easily. Tacit knowledge is personal, context-specific, and therefore difficult to formalise and communicate. It is personal knowledge embedded in individual experience and involves intangible factors such as personal belief, perspective, and the value system. Tacit knowledge is difficult to communicate and share in the organisation and must thus be converted into words or numbers that anyone can understand.

Nonaka and Konno (1998) describe two dimensions to tacit knowledge. The first dimension is the technical dimension, which encompasses the kind of informal personal skills or crafts often referred to as "know-how". The second dimension is the cognitive dimension, which consists of beliefs, values, ideals and mental models that are deeply ingrained and which we often take for granted. They argue further that this cognitive dimension of tacit knowledge shapes the way we perceive the world. This kind of knowledge could also be defined as procedural knowledge used in problem solving and decision making (Nonaka, 1995), (Firebaugh, 1989). According to Nonaka and Takeuchi (1995) organisational knowledge is created during the time the "conversion" takes place, i.e. from tacit to explicit and back again into tacit. The interaction between these two forms of knowledge is the key dynamic of knowledge creation in the organisation.

\section{Knowledge Conversion}

Knowledge conversion is a "social" process between individuals and is not confined to one individual. Assuming that knowledge is created through the interaction between tacit and explicit knowledge four different modes of knowledge conversion are possible (Figure 2). The content of the knowledge created by each mode of knowledge conversion is naturally difficult, which creates different contents of knowledge (Nonaka and Takeuchi, 1995):

1. From tacit knowledge to tacit knowledge (socialisation that creates sympathised knowledge). The socialisation mode usually starts with building a "field" of interaction. This field facilitates the sharing of members' experiences and mental models. Socialisation involves the sharing of tacit knowledge between individuals.

2. From tacit knowledge to explicit knowledge (externalisation that creates conceptual knowledge). The externalisation mode is triggered by meaningful "dialogue or collective reflection," in which using 
appropriate metaphor or analogy helps team members to articulate hidden tacit knowledge that is otherwise hard to communicate. Externalisation requires the expression of tacit knowledge and its translation into comprehensible forms that can be understood by others.

3. From explicit knowledge to explicit knowledge (combination that creates systematic knowledge). The combination mode is triggered by "networking" newly created knowledge and existing knowledge from other groups in the organisation, thereby crystallising them into a new product or service.

4. From explicit knowledge to tacit knowledge (internalisation that creates operational knowledge). "Learning by doing" triggers internalisation. The internalisation of newly created knowledge is the conversion of explicit knowledge into the organisation's tacit knowledge. In practice, internalisation relies on two dimensions. First, explicit knowledge must be embodied in action and practice. Second, there is a process of embodying the explicit knowledge by using simulations or experiments to trigger learning by doing processes.

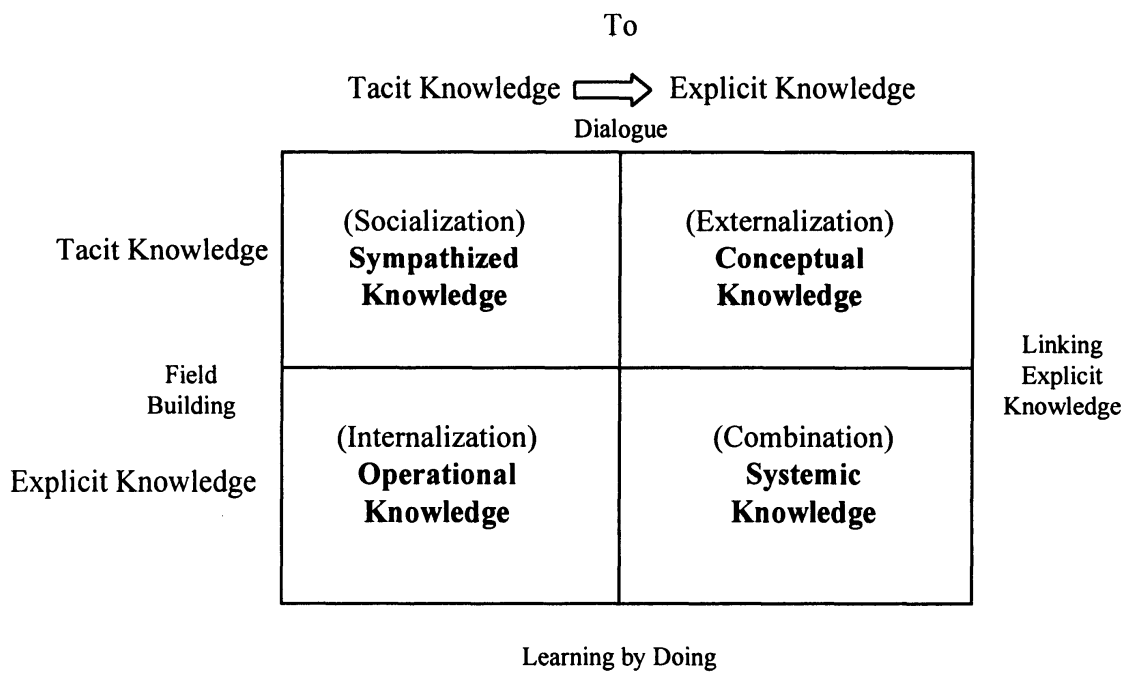

Figure 2. Contents of knowledge created via the four modes (Nonaka and Takeuchi, 1995)

This study is focused on the process issues of knowledge creation in SPI, the actors involved, and the conversion of new or modified knowledge between different organisational levels. We interpret changes in practitioners' understanding of the software processes, and changes in practice as indicators of new tacit knowledge, and new guidelines, policies, and manuals as new explicit knowledge. 


\section{THE CASE}

This study was performed at AstraZeneca one of the world's leading pharmaceutical companies. AstraZeneca is a research-driven organisation with a formidable range of products designed to fight disease in important areas of medical need. The company was formed in April 1999 by the merger of Astra $\mathrm{AB}$ and Zeneca Group PLC. AstraZeneca has a strong research base and powerful product portfolio, designed in seven areas of true medical need - cancer, cardiovascular, central nervous system, gastrointestinal, infection, pain control and, and respiratory. AstraZeneca is globally number three (1999) in ethical pharmaceuticals and has more than 50,000 employees worldwide. It has research and development (R\&D) centers of excellence in Sweden, UK and the USA and R\&D headquarters in Södertalje, Sweden. The company has some 10,000 R\&D personnel and a US $\$ 2$ billion R\&D investment in 1999, extensive global sales and marketing network, employing over 25,000 people, and 12,000 people employed in production in 20 countries.

\subsection{The Software Organisation}

AstraZeneca has four departments that supply global IT services to the whole company: one in the UK, one in the USA, one in Sweden and one to provide IT support for research and development for the whole organisation. In addition to this, there are five global supplier managers who have the responsibility of controlling the needs of IT services in the business functions in the company. Furthermore, there is a company staff with central IT departments for solving problems related to technology adoptions, infrastructure, security, integration, and strategies. Beyond all this, there are IT functions that support the local marketing company in the respective countries. There are in total 2,500 persons working with IT-related questions in AstraZeneca.

This research started before the merger between the two companies in an IS organisation called Clinical Research and Information Management (CRIM) at the former Astra Hässle in Sweden and continued later in the new IS organisation, which then changed its name to Development IS (DevIS). DevIS supports clinical and pharmaceutical projects, Regulatory Affairs and Product Strategy and Licenses at AstraZeneca R\&D Mölndal. DevIS is also responsible for influencing the development of the global clinical research processes and IS/IT tools in AstraZeneca. DevIS comprises 90 people including contractors, most of whom have backgrounds in IS/IT.

Many regulatory authorities require that pharmaceutical companies and their software organisations comply with GXP (Good Manufacturing 
Practice, Good Clinical Practice, and Good Laboratory Practice) rules. GXP rules are the authorities' quality requirements to pharmaceutical companies for ensuring patient health, the quality of processes (e.g. clinical studies or software development) and the quality of products (e.g. tablets or software). As a software organisation in the pharmaceutical business, DevIS must address many quality requirements. One fundamental requirement is that DevIS must be able to show the authorities, by documented evidence, that software development activities (e.g. software change control, software validation, and data processing and storage) are being performed in compliance with quality requirements. Therefore every software project regulated by GXP requirements should carefully apply all quality rules and be able to show by documented evidence that the software is compliant with the related GXP requirements. The company long ago adopted standard operation procedures that explicitly describe the company's software quality rules. These standard operation procedures should be applied in all information systems regulated by GXP requirements.

Employees of DevIS are basically engaged with software development, software maintenance and software operation activities. The software development activities occur in two forms: 1 ) development of totally new software products (software development) and 2) developing or changing existing software products (software maintenance). A typical software development project at DevIS is scheduled to take between six months and one year and includes analysis, design, construction, testing, and validation. Software maintenance activities can consist of changes in the code or developing a completely new application for existing software products. Software products in DevIS include the software and all related documentation (e.g. user requirement specification, test plan, validation plan, validation report, user manuals etc.).

\subsection{The Problem Area}

The results of a problem analysis performed in early 1999 in one software development group within DevIS showed a need for improving software project disciplines and providing guidelines to understand the standard operation procedures and GXP rules. The director of DevIS initiated an improvement project called Software Process Improvement at DevIS (SPID) to understand the existing problems and improve the organisation's software processes. The following figure illustrates a rich picture of the SPID project. 


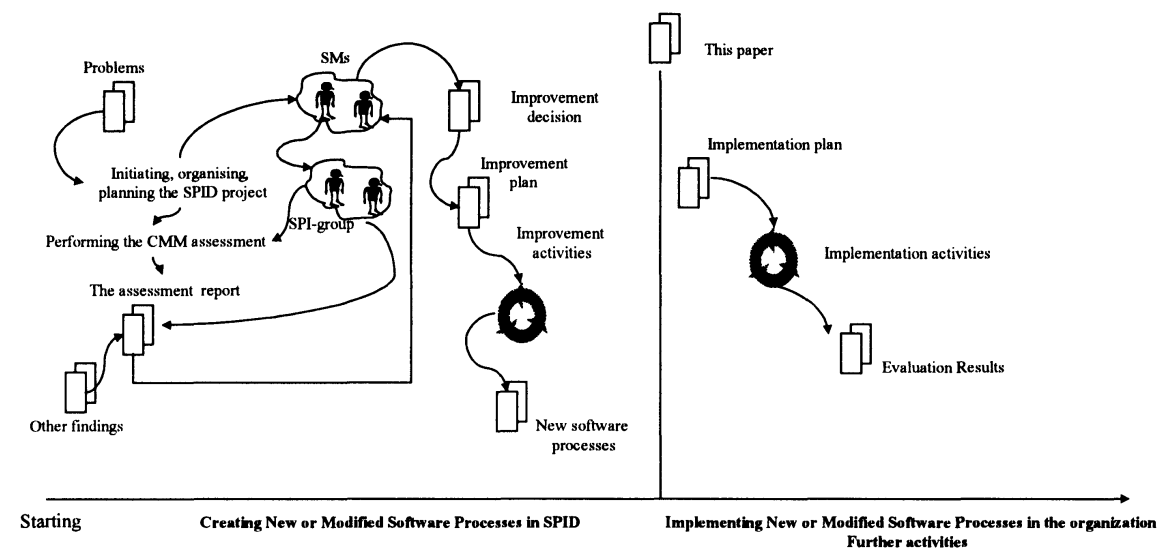

Figure 3. The rich picture of SPID (see Checkland 1990)

The SPID project was initiated, organised, planned, and performed during the period of April 1999 to May 2000 and aimed to improve DevIS' software processes. A maturity assessment using a modified CMM-based (Capability Maturity Model) assessment method, QBA (see [1996), showed that DevIS was by then a level one organisation and addressed improvement possibilities in all analysed KPAs (Key Practice Areas). An improvement report based on the assessment's findings and other findings from earlier improvement initiatives at DevIS addressed six improvement activities. The steering committee of SPID gave priority to the following improvement activities (improvement decision) from the improvement report:

1. To establish a minimum documentation level for documenting the results of software projects and create the software documentation process.

2. To improve processes for software validation, software change management, and document version control.

3. To create a template library including templates for documentation of software development activities, such as: user requirement specification, design specification, test plan, and validation plan.

The SPI group including (5 software engineers, 2 assisting consultants, and the author) started planning and performing improvement activities over a four-month period. This initial phase of SPID was scheduled to be finished in June 2000. The implementation activities for implementing the newly created software processes in the whole organisation start in August 2000. 


\section{DISCUSSION}

This section discusses SPID on the basis of knowledge creation framework described earlier in this paper. We present a map illustrating the knowledge creation process in SPID including the software process improvement steps, the knowledge creation processes, the knowledge created, and the actors and the organisational levels involved.

During the initiating phase, we realised that the standard CMM maturity assessment developed by the SEI (see Zubrow et. al. 1994) was too general for our situation. We adapted a simplified CMM-based assessment method, QBA (see Arent and Iversen, 1996), that focuses on level two and modified it to fit DevIS's terminology and needs. The assessment indicated that we needed to focus more on software validation, change, and version control, and on creating templates rather than on processes related to project management (e.g. software project planning, software project tracking and oversight). The software organisation aimed to create only a few processes based on practitioners' experiences and the organisation's quality requirements. The SPI-group working with improvement activities spent a grate deal of time studying and understanding the CMM, the organisation's quality requirements, the organisation's existing standards, and the software engineering literature to create its own understanding of what is needed to create the new processes.

However, we succeeded by following the IDEAL model in organising and planning for the performance of the improvement activities (the I, D, E and partly A, and L steps in IDEAL) in a systematic way. This allowed us to see very early in the project the starting point, the finishing point and all activities included in reaching our targets. We followed IDEAL's main steps very naturally and learned how to systematically go about creating the new or modified software processes. However, the path from knowing what to do to doing it in practice was neither easy nor clear.

\subsection{The knowledge creation process in SPID}

According to the organisational knowledge creation framework presented earlier in this paper, the organisational knowledge creation process starts at the socialisation phase at the group level and continues to the externalisation phase, aiming to create new explicit knowledge based on the interaction between tacit and explicit knowledge. The created explicit knowledge will, then be combined with other already existing explicit knowledge in the organisation. The new or modified knowledge is subsequently put into practice through learning by doing to become tacit knowledge. 
In our software process improvement project the first organisational knowledge creation process started in the socialisation phase creating sympathised knowledge about the SPI concept through interaction between tacit to tacit knowledge. The author arranged meetings with the management to introduce the concept of SPI (creating SPI-knowledge). These meetings were held on an individual level between the director of the software organisation, other software managers, and the author aiming to learn about the SPI and the possibilities for gaining benefits by doing an SPI project. Other meetings with the same contents were held with the SPI-group for similar purposes. The created tacit SPI-knowledge then became explicit SPIknowledge through a dialogue in the externalisation phase in which conceptualised knowledge was created mostly by the author, the software managers, and the assisting consultants. The author arranged other meetings to identify the initial improvement infrastructure needed to carry out the project. The created SPI-knowledge in this phase was mostly in the form of project specifications including information about the SPI plan, resources needed, role descriptions, goals, and responsibilities. The created explicit SPI-knowledge (the project specification) was then combined with other existing knowledge and experience in improving software processes, and other improvement models at the software organisation to create systematic knowledge. In this phase (combination), knowledge was created mostly at the individual and group levels through a dialogue between all actors. The operational SPI-knowledge was then created through practising software process improvement activities. The author, the software engineers, the software managers, and the assisting consultants were all involved in making SPI happen in the organisation. In this phase the created explicit SPIknowledge became tacit SPI-knowledge through practice. This means that, in our software process improvement project, all organisational knowledge creation phases involved all actors in individual and almost group levels in the creation of SPI-knowledge.

The other organisational knowledge creation process in our project deals with creating SE-knowledge (Software Engineering Knowledge). This process also started in the socialisation phase through externalisation, and combination to create SE-knowledge. A modified CMM assessment done in three software projects involving three software project managers and two software developers to identify the current level of software process problems. The results and the recommendations of the assessment were identified and documented. This action led to the creation of the first explicit SE-knowledge about the current maturity level of the organisation based on the results of the assessment. The author and the assisting consultants were involved in creating this knowledge. This knowledge was then combined and integrated with other organisational requirements, and findings from earlier 
improvement activities. The author interpreted the authorities' and organisation's quality requirements on software development practice and created explicit knowledge about the quality requirements in an individual level. The created knowledge about the quality requirements, earlier improvement findings, and assessment findings were summarised on an improvement suggestion report created by the author and the assisting consultants and presented to management for a decision. The created explicit SE-knowledge was then transferred to group levels when the author held presentations to give results of the assessment in different meetings for different groups. This explicit SE-knowledge was then used by the SPIgroup as input to create the minimum baseline level for documentation and other new software processes.

The next step involved the process of capturing practitioners' ideas about software practices and forming them into explicit knowledge. The author arranged meetings in which the software engineers and project managers shared their experiences and ideas about the software processes (in the socialisation phase). We focused in this phase on creating a common understanding of the software process problems and get agreeing on the ideal software processes. In the next phase (externalisation) we focused on creating explicit knowledge about the new software processes based on the practitioners' ideas. We created some drafts for the new processes and discussed and changed the contents of the processes several times until we could agree upon an acceptable level. This explicit SE-knowledge was created by the SPI-group at the individual and group levels. The software managers were not involved in creating SE-knowledge. This phase was one of the most important and also one of the most difficult phases in our SPI project. This suggests that such a project should not create new processes and standards detached from practices. New or modified processes should be created based on practitioners' experiences from practice. This suggestion is supported in several studies that indicate that routines and standards are learned and developed in practice, not from formal explicit standards procedures (Brown and Duguid, 1991), (Arent and Norbjerg, 2000). 
The following tables illustrate the knowledge creation process in our project: *: Total, : Partly, -: Nothing.

SPID: Software Process Improvement at Development IS (our SPI project)

SPIer: Software Process Improver, (the author)

SMs: Software Managers

SPICs: Software Process Improvement Consultants: (the assisting consultants)

SEs: Software Engineers

OKCL: Organisational Knowledge Creation Level

Ind.: Individual, Gro.: Group, Org.: Organisational

OKCP: Organisational Knowledge Creation Process

Soc: Socialisation, Ext.: Externalisation, Comb.: Combination, Intern.: Internalisation

\begin{tabular}{|c|c|c|c|c|c|}
\hline SPrPhase & SPTAetrivite & 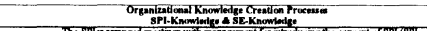 & Soe.ExkComil,Inturn. & $\begin{array}{l}\text { OKCL } \\
\text { Int.Gra Ors }\end{array}$ & Splorsmestesticoss \\
\hline \multirow[t]{3}{*}{ Tnitiating } & \multirow{3}{*}{ 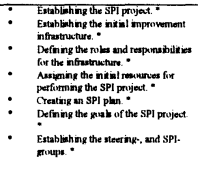 } & 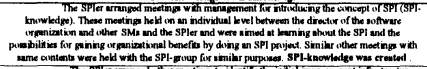 & & & \\
\hline & & 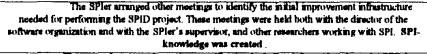 & & & \\
\hline & & 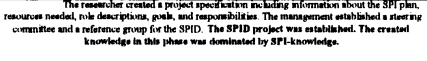 & & & \\
\hline \multirow[t]{3}{*}{ Disknemeting } & \multirow{3}{*}{ 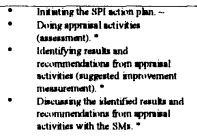 } & 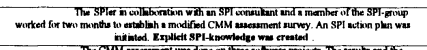 & & & \\
\hline & & 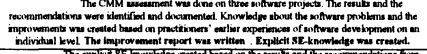 & & & \\
\hline & & 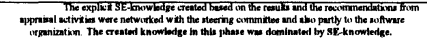 & & & \\
\hline \multirow[t]{3}{*}{ Extoilliking } & \multirow{3}{*}{ 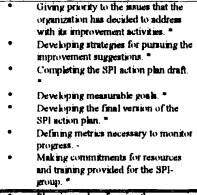 } & 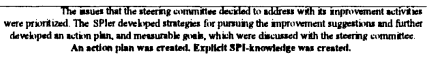 & & & \\
\hline & & 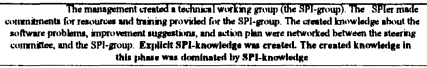 & & & \\
\hline & & & & & \\
\hline Acting & 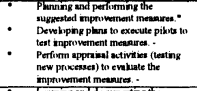 & 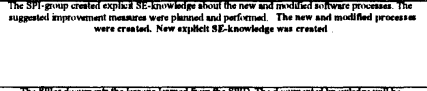 & & & \\
\hline \multirow[t]{2}{*}{ Larring } & \multirow{2}{*}{ 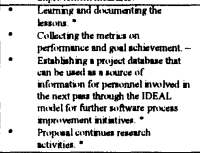 } & 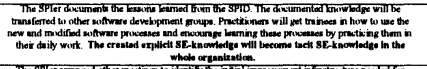 & & & \\
\hline & & 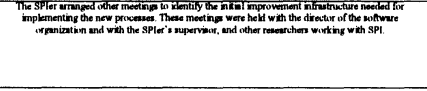 & & & \\
\hline
\end{tabular}

Figure 4. The organisational knowledge creation process in SPID 


\section{LESSONS LEARNED}

We have analysed a software process improvement project from an organisational knowledge creation perspective using a framework based on Nonaka and Takeuchi (1995) of organisational knowledge creation process. From the perspective of this framework we believe that it is useful to view such a project as an organisational knowledge creation process. On the basis of our experiences from this study we believe that certain types of created knowledge within an SPI project deal with the fundamentals of Software Process Improvement (SPI-knowledge) such as: management of SPI initiatives, issues related to how such an initiative should be guided, and issues related to SPI's focus on target(s) (see Aaen et al., 2000). Others deal with issues related to Software Engineering practice (SE-knowledge) such as: project planning, quality assurance, change control, and configuration management (see Pressman 1997).

To illustrate the knowledge creation process we have applied the Nonaka and Takeuchi's framework to one SPI project and created a map illustrating: the software process improvement phases, the activities, the created knowledge, the actors involved, and the organisational levels on which knowledge is created. On the basis of our experiences from this study we suggest a number of lessons relevant for future software process improvement projects, the SPI practice, and the effect of organisational knowledge creation on SPI.

Lesson one: Two related knowledge domains (Software Process Improvement (SPI)-, and Software Engineering (SE)-knowledge) are involved in the knowledge creation process in an SPI project. Two types of knowledge, i.e. SPI-, and SE-knowledge, play an essential role in SPI activities and the knowledge creation practice involved in an SPI project. The knowledge creation behaviour is completely different in these two knowledge domains.

Lesson two: a: The project manager of the SPI project, software managers, and assisting consultants are the key actors involved in the creation of SPI-knowledge. The most involved actors in creating SPIknowledge during the very initial phase of the project are the SPI project manager, and the software managers. The SPI-knowledge is created mostly during the initiating, establishing, and learning phases. The SPI project manager is most involved in creating SPI-knowledge. The assisting consultants and the software managers contribute to combining the SPIknowledge with their ideas and experience. Later on in the project other actors will become involved in the knowledge creation process.

Lesson two: b: The software engineers and the SPI project manager are the key actors involved in the creation of SE-knowledge. The SE-knowledge 
is created primarily during the diagnosing, acting, and learning phases. During the diagnosing phase the SPI project manager, the software engineers, and the assisting consultant are involved. Later on in the project only the SPI project manager and the software engineers are involved in the creation of SE-knowledge. SE-knowledge is created on the basis of software engineers' experience and ideas about software processes. The software managers are not involved in any phases of the project for creating SEknowledge.

Lesson three: a: The knowledge creation process in the case of SPIknowledge happens mostly on the individual level and sometimes on the group level. The very first SPI-knowledge is created on an individual level through interaction between the SPI project manager, and the assisting consultants. This knowledge is then transferred to the group level in which the software managers are involved.

Lesson three: b: The knowledge creation process in the case of SEknowledge happens mostly on the group level and sometimes on the organisational level. SE-knowledge about current software process problems and new software processes is created on the basis of software engineers' ideas on a group level. This knowledge is then transferred to other organisational levels.

These lessons agree with Nonaka and Takeuchi's suggestion of starting the organisational knowledge creation process at the socialisation phase on the team level. However, in our SPI project, creating SPI-knowledge started in the socialisation phase on the individual level and then passes through almost all other organisational knowledge creation phases to the group level. Creating SE-knowledge in our project also started in the socialisation phase mostly on the group level and then passes through almost all other organisational knowledge creation phases to the organisational level. If an SPI project ends before an implementation of the new software processes in the whole organisation (as it did for us) then the internalisation of the SEknowledge might happen only during a test period in a pilot project (if any) in the improvement phase. The organisational knowledge creation process for SE-knowledge passes to the organisational level first when the created software processes are implemented in the whole organisation to become a part of all practitioners' daily work.

The implementation of newly created software processes is an issue of implementing changes in practitioner's daily work. These changes should be organised, planned, and implemented in the whole organisation to be a part of the organisation's daily practice. As mentioned before, one great challenge for DevIS is to find a way to implement the new or modified software processes in the organisation. An important question for further research is how can theories such as organisational learning and change 
management support, understand, and enhance implementation initiatives of new processes at DevIS?

\section{ACKNOWLEDGEMENT}

This research was sponsored by AstraZeneca R\&D Mölndal in Sweden in collaboration with the Viktoria Institute and the Institute of Computer Science in Aalborg, Denmark.

\section{REFERENCES}

Aaen I., Arent J., Mathiassen L., Ngwenyama O.: A Conceptual MAP of Software Process Improvement. Artikelsamling, Center for Softwareprocesforbedring. Dansk Elektronik, Lys \& Akustik. 2000.

Ami: Ami, application of metrics in industry. A Qualitative Approach to Software Management, CSSE South Bank University, London. 1992

Aren J. and Norbjerg J: SPI as Organizational Knowledge Creation: A Multiple Case Analysis. Proceedings Conference Proceedings at Maui Hawaii, January 2000.

Arent J., Iversen J., Development of a Method for Maturity Assessments in Software Organizations based on the Capability Maturity Model, in Department of Computer Science. Aalborg: Aalborg University, 1996.

Bach James: The Immaturity of the CMM. American Programmer. 1994

Baskerville, R. \& A. T. Wood-Harper, A Critical Perspective on Action Research as a Method for Information Systems Research Journal of information technology, Vol 11, 1996.

Checkland Peter, Scholes Jim: Soft System Methodology in Action, John Wiley \& Sons LTD. England.

Cook S.D.N. and Brown J.S., Bridging epistemologies: The generative dance between organizational knowledge and organizational knowing, Organization Science 10, No 4, 381-400, 1999.

Curtis, B.: Improving software organizations with the CMM. Seminar. 1996.

Debou, C.: SPI Success Factors: Toward More Business Orientation. Software Process Newsletter, 10, 15-18. 1997.

Firebaugh, M. W.: Artificial Intelligence - A Knowledge-Based Approach. Boston: PWSKENT Publishing Company. 1989.

Goldenson, D. R., and J. D. Herbsleb.: After the Appraisal: A Systematic Survay of Process Improvement, its benefits, and Factors that Influence Success. CMU/SEI-95-TR-009, SEI, Pittsburgh. 1995.

Gremba Jennifer and Myres Chuck: The IDEAL Model: A Practical Guide for Improvement, Software Engineering Institue, Cornegie Mellon University. 1997.

Halloran, P.: Organizational Learning from the Perspective of a Software Process Assessment \&Improvement Program." A paper delivered at the HICS 1999, Hawaii, 1999.

Hayes Will, Zubrow Dave: Moving On Up: Data and Experience Doing CMM-Based Process Improvement, Technical Report CMU/SEI-95-TR-008, August 1995.

Herbsleb, J., et al.: Software Quality and the Capability Maturity Model. Communications of the ACM, 40(6), 30-40. 1997. 
Humphrey, Watts S.: Managing the Software Processes, Addison-Wesley Publishing Company, USA. 1989.

Johansen, J., and L.: Mathiassen. Lessons learned in a National SPI Effort. EuroSPI 98 Göteborg. 1998.

Kuvaja Pasi, Bicego: BOOTSTRAP - a European assessment methodology, Software Quality Journal 3, 117-127. 1994.

Larsen E., Kautz K: Quality Assurance and Software Process Improvement in Norway, Software process improvement pract. , 3, 71-86 1997

Mathiassen, L: Reflective systems Development. Dr. Thechn. Thesis, Aalborg University, Danmark, www.cs.auc.dk/ larsm. 1998.

McFeeley Bob: IDEAL: A User's Guide for Software Process Improvement, Software Engineering Institue, Cornegie Mellon University. 1996.

Mashiko, Y., and V.R. Basiili: Using the GQM Paradigm to Investigate Influential Factors for Software Process Improvement. Journal of Systems and Software, 36. 17-32. 1997.

Nonaka I. And Konno N.: The Concept of "Ba": Building a Foundation for Knowledge Creation, California Management Review Vol 40, No.3, Spring 1998

Nonak, I., and Takeuchi H.: The Knowledge-Creating Company, Oxford University Press, Inc. 1995.

Paulk C. Mark: Foreword (Software Process Improvement, Sami Zahran 1998 Practical Guidelines for Business Success, Addison Wesley Longman), Software Engineering Institute, Pittsburgh, Pennsylvania, USA Software Process Improvement. 1997.

Paulk Mark C., et al:: The Capability Maturity Model for software Version 1.1, Carnegie Mellon University, Software Engineering Institute. 1993.

Polanyi, M., : The Tacit Dimension. London: Routledge \& Kegan Paul. 1966.

Pressman Roger S.: Software Engineering, a practitioner's approach, fourth edition, International editions. 1997.

Stelzer, D., Mellis, W., and Herzwurm, G.: "Technology Diffusion in Software Development Processes: The contribution of Organizational Learning to Software Process Improvement." In Information Systems Innovation and Diffusion: Issues and Directions, ed. T. Larsen and E. McGuire, 297-344. Hershey, Usa: idea Group Publisher, 1998.

TickIT, TickIT: Guide to Software Quality Management System Construction and Certification using ISO 9001:1994. Issue 1.0, DISC TickIT Office, November. 1995.

Thomson Helen E., Mayhew Pam: Approaches to Software Process Improvement, Software Process-Improvement and Practice, Vol. 3, 3-17. 1997.

Wohlwend H. and Rosenbaum S: Schlumberger's Software Improvement Program, IEEE Transactions on software engineering, Vol 20. No. 11. November 1994

Zubrow David et.al.: Maturity Questionnaire, Special Report CMU/SEI-94-SR-7, Software Engineering Institute. 1994. 